\title{
IMPACT OF RYe Rolling DiRECTION AND DifFERENT No-Till Row CleANers on CotTon EMERGENCE AND Yield
}

\author{
T. S. Kornecki， R. L. Raper, F. J. Arriaga，E. B. Schwab, J. S. Bergtold
}

\begin{abstract}
Cover crops have been recognized as a vital component of conservation agriculture. However, cover crops must produce substantial biomass to be effective. Because of the large amount of residue produced by many cover crops, they must be managed appropriately to avoid planting problems. Roller-crimpers have been used to manage cover crops by flattening them and creating a thick mat over the soil surface. A study was conducted to determine the effect of different rolling directions (parallel, diagonal, and perpendicular to cotton planting direction) using a roller/crimper, three different commercial row cleaners (Dawn, Dawn without coulter, and Yetter), and no row cleaner on cotton (Gossypium hirsutum L.) stand, emergence rate, yield, and net returns. The study was conducted at two Alabama locations with a replicated strip plot design. Presented results illustrate two growing and harvest seasons (2004 and 2005). Rye (Secale cereale L.) was chosen as the cover crop due to its potential to produce large amounts of biomass and its popularity with Alabama producers. Rye was rolled at the soft dough growth stage and terminated using Roundup (glyphosate). Data showed that parallel rolling with respect to the planting direction for cotton produced the highest cotton stand and yield in both years. In 2004, the Yetter row cleaner resulted in higher cotton stand and yield for both locations when compared with the Dawn row cleaner. However, in 2005, the Dawn row cleaner resulted in a greater cotton yield than the Yetter. Based on the emergence rate index (ERI), the most rapid emergence was observed with parallel rolling and both row cleaners. The slowest emergence rate was observed with perpendicular and diagonal rolling and no row cleaners. Parallel rolling minimized accumulated rye residue on the row cleaners and minimized the cleaning time for the row cleaners. General findings from this research are: for tall rye producing large biomass, parallel rolling and Dawn or Yetter row cleaners are recommended. For shorter rye producing low biomass, no row cleaners were required for rolled rye with the parallel rolling direction, or cotton could be planted into standing rye using Dawn or Yetter row cleaners. Regardless of the height and amount of rye residue and the row cleaner type, the perpendicular and diagonal rolling directions are not recommended.
\end{abstract}

Keywords. Cover crop, Conservation system, Economics, Roller/crimper, Row cleaner, Rolling direction.

I n the southeastern U.S., between 1990 and 2004, cropland area planted in conservation systems increased from 5.7 to 7.0 million hectares (CTIC, 2004). This increase is likely related to an increase in the adoption of winter cover crops, an integral part of conservation tillage systems. Major benefits of cover crops include weed suppression from allelopathy and mulch effects, as well as improvements in soil properties due to increased soil organic matter. Several studies have identified other benefits, such as increased water infiltration, reduced runoff, reduced soil erosion, reduced impact of soil

Submitted for review in April 2007 as manuscript number PM 6978; approved for publication by the Power \& Machinery Division of ASABE in March 2009.

The use of trade names or company names does not imply endorsement by the USDA-ARS.

The authors are Ted S. Kornecki, ASABE Member, Agricultural Engineer, Randy L. Raper, ASABE Member Engineer, Agricultural Engineer, Francisco J. Arriaga, ASABE Member, Soil Scientist, Eric B. Schwab, Agronomist, USDA-ARS National Soil Dynamics Laboratory, Auburn, Alabama; and Jason S. Bergtold, Agricultural Economist, Kansas State University, Manhattan, Kansas. Corresponding author: Ted S Kornecki, USDA-ARS National Soil Dynamics Laboratory, 411 South Donahue Drive, Auburn, AL 36832; phone: 334-844-4741; fax: 334-887-8597; e-mail: tkornecki@ars.usda.gov. compaction, and improved crop yield stability (Kern and Johnson, 1993; McGregor and Mutchler, 1992; Reeves, 1994; Raper et al., 2000a; Raper et al., 2000b, Ashford and Reeves, 2003; Dinnes et al., 2002; Kasper et al., 2001; Snapp et al., 2005).

Rye (Secale cereale L.) is a commonly used winter cover crop in the Southeast. To maximize benefits from rye, the cover must be terminated at the appropriate growth stage and in sufficient time for water recharge before planting of a cash crop, such as cotton or corn. According to Ashford and Reeves (2003), an appropriate growth stage for rye termination is soft dough, a maturity stage that provides optimum levels of rye biomass. Most agricultural extension services recommend terminating the cover crop at least two weeks prior to planting. This is important to prevent the cover crop from competing for valuable soil moisture and nutrients with a planted cash crop (Hargrove and Frye, 1987).

Large amounts of cover crop residue can create problems with any tillage practice that must be conducted in the spring, prior to planting operations. Thus, cover crops must be managed appropriately to prevent planting problems. The most common problem is "hair pinning," in which residue is pushed into the soil rather than being cleanly sheared. "Hair pinning" creates a condition in which the seeds are unable to have good seed-soil contact. As a result, skips in planted rows 
of the cash crop can occur, negatively impacting crop emergence and yield. Another major problem is accumulation of cover crop residue on planting units, which may result in frequent stops to clean the equipment, thus increasing the time needed to plant a cash crop.

In the U.S., cover crops have commonly been terminated with herbicides, since spraying is relatively fast and effective. Another effective way to manage cover crops is mechanical termination using rollers/crimpers. Rolling technology originated in Brazil, where rollers have been used successfully for many years with conservation agriculture (Derpsch et al., 1991). Rollers typically consist of a steel drum with attached crimping bars equally spaced on the drum's perimeter (fig. 1). Managing cover crops using improved rolling technology has been introduced in the southern U.S. (Raper et al., 2004; Kornecki et al., 2006). Rollers have been shown to be beneficial by flattening the cover crop to provide a flat mat over the surface of the field and preventing multiple-direction lodging. However, no information is available to assist producers with selecting the direction of rolling relative to planting operations. Commercial row cleaner attachments are available to producers, but no data exist regarding performance of these row cleaners in different rolling patterns with varying amounts of residue. Therefore, the objectives of this study were: (1) to determine the effect of different rolling directions relative to cotton planting direction on cotton stand, emergence rate, and yield; and (2) to evaluate different commercially available row cleaner attachments on cotton stand, emergence rate, yield, and net returns from a no-till production system.

\section{Materials ANd Methods}

To account for different soils and climatic conditions, two experimental sites were chosen for this study: the E.V. Smith Research and Extension Center (EVS) at Milstead (central Alabama), and the Tennessee Valley Research and Extension Center (TVS) at Belle Mina (northern Alabama). Rye (Secale cereale L.) was planted at both locations in the fall of 2003 and 2004 using a grain drill with row spacing of $19 \mathrm{~cm}$. Rye was rolled/crimped in the spring (mid-April) of 2004 and 2005 at the soft dough growth stage, a desirable period for termination that normally produces an optimum level of biomass (Nelson et al., 1995). Rolling rye formed a thick protective mat mulch on the soil surface and was performed using an experimental three-section, $4.1 \mathrm{~m}$ wide roller (Bigham Brothers, Lubbock, Texas) with long straight crimping bars (fig. 1). Cover crop standing height and biomass samples were collected at the time of termination for each plot.

Following rolling, the cover crop was sprayed with herbicide (glyphosate) at a rate of $1.64 \mathrm{~L}$ (active ingredient) per hectare. Applying herbicide to terminate winter cover crops following rolling operation is a common practice in Alabama since it ensures senescence of the cover crop and thus reduces soil moisture competition with the cash crop. Rolling the cover biomass speeds up the cover termination process, forming a dense mat that reduces weed competition and evapotranspiration during the growing season. Cotton (Stoneville 5242BR) was planted using a four-row John Deere MaxEmerge Plus vacuum planter after rye was desiccated and soil moisture conditions were adequate for planting ( 3 weeks after rolling). During planting, various row cleaner attachments were used. The amount of residue that

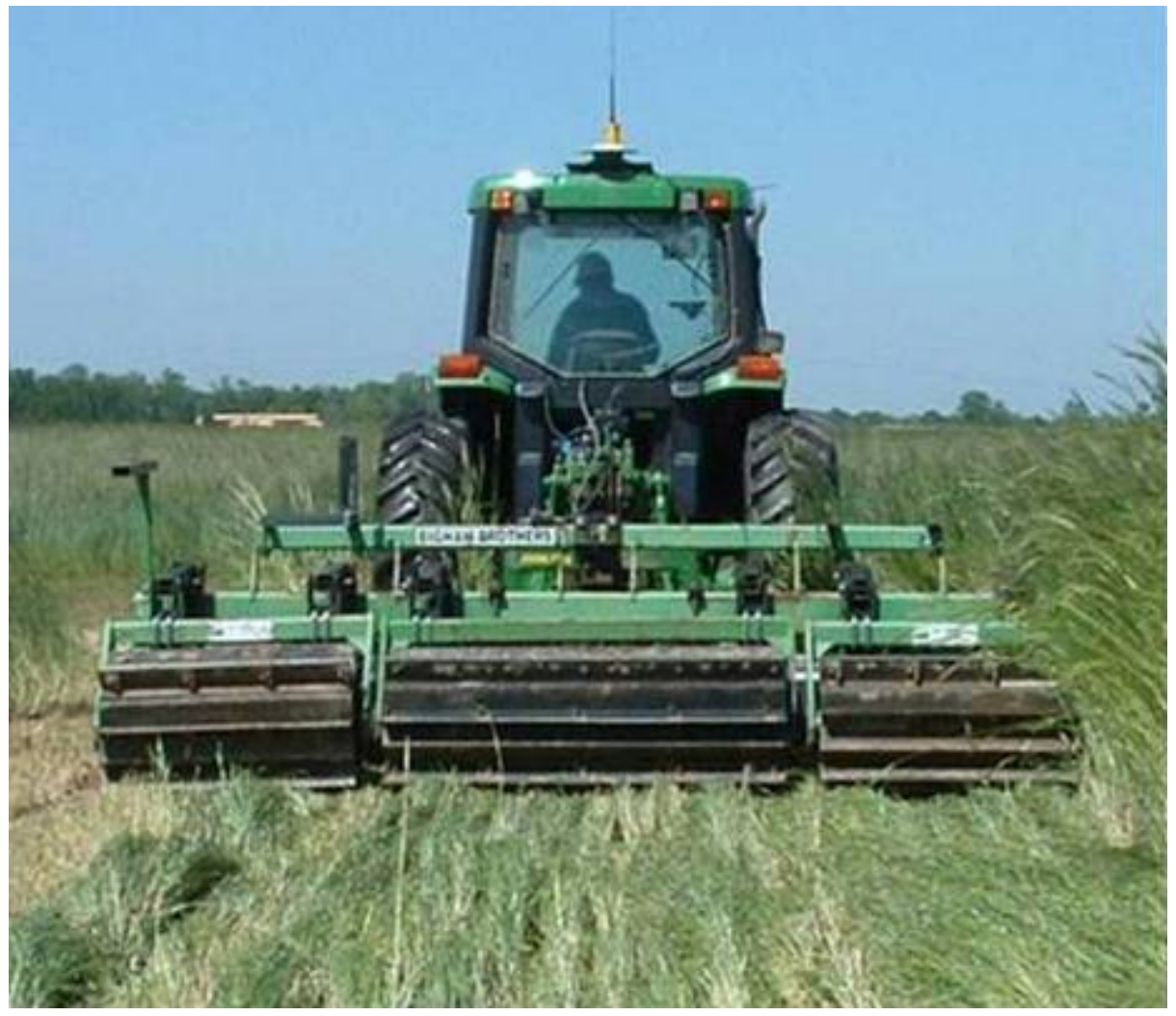

Figure 1. Three-section roller with straight crimping bars $4.1 \mathrm{~m}$ wide. 
accumulated on the row cleaners and the time required to remove residue were recorded for each plot. Cotton stand (number of plants) was measured several times during plant emergence period using a $1.5 \mathrm{~m}$ long ruler. The ruler was positioned parallel to the cotton row at three random locations, and the number of emerged plants was counted along the ruler's length in the two middle rows in each four-row plot. To compare plant emergence rates across treatments, the emergence rate index (ERI) was calculated using the procedure described by Erbach (1982), i.e.:

$$
\mathrm{ERI}=\sum_{n=f i r s t}^{\text {last }} \frac{[\% n-\%(n-1)]}{n}
$$

where

$\% n=$ percentage of plants emerged on day $n$

$\%(n-1)=$ percentage of plants emerged on day $(n-1)$

$n \quad=$ number of days after planting

first $=$ number of days after planting that the first plant emerged (first counting day)

last = number of days after planting when emergence was considered complete (last counting day).

Cotton was harvested in the fall of 2004 and 2005 using a two-row John Deere 9920 cotton picker. The two middle rows from each four-row plot were harvested and bagged in the field. Bags were then weighed in order to determine seed cotton yield.

The experiment was a strip plot design with four replications for each treatment. Four different treatments for rolling direction (main effects) were used with respect to the cotton planting direction (driving north): no rolling (standing rye), parallel (rolling rye and planting cotton done in the same direction, both driving north), perpendicular, and diagonal $\left(45^{\circ}\right.$ angle between rolling direction, driving northeast, and planting direction, driving north). For subplots in this experiment, three different commercially available row
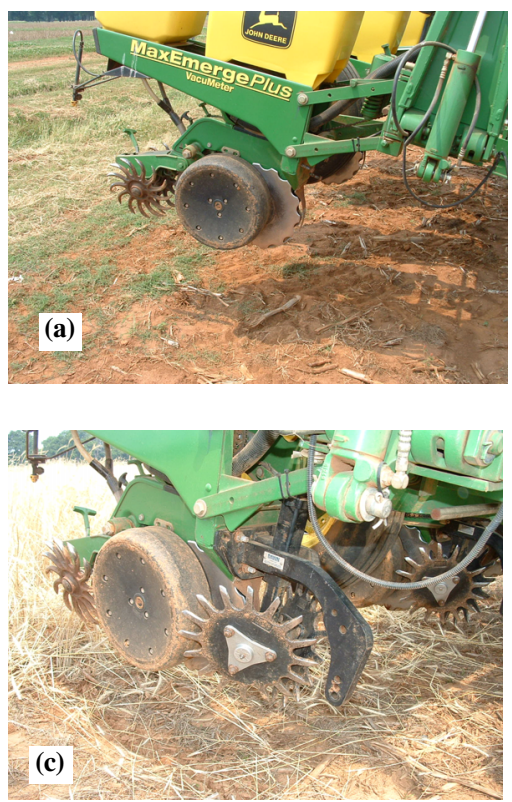

Figure 2. Row cleaners: (a) basic planting unit with no row cleaner, (b) Dawn, (c) Dawn/no coulter, and (d) Yetter.

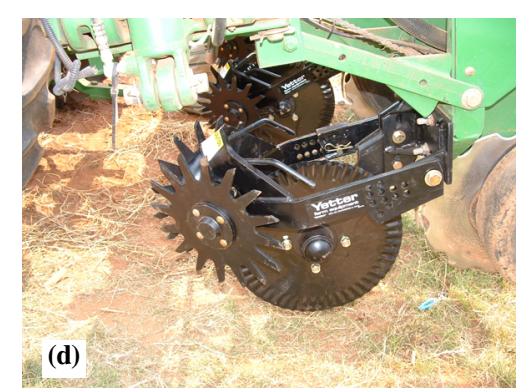

cleaner attachments were used. Row cleaner types used in both locations and years are shown in figure 2. The following configurations were employed: (a) no row cleaner using basic John Deere MaxEmerge Plus planting unit with double disk openers, rubber gauging wheels, spiked furrow closing wheels, and two seed-firming plastic strips; (b) Dawn row cleaner with coulter; (c) Dawn row cleaner with coulter removed; and (d) Yetter row cleaner.

Changes in net returns of each treatment from the control (no rolling, no row cleaner) were calculated using a partial budgeting approach. Change in net returns were equal to the difference in revenues from cotton production between the treatment and control minus the additional cost of rolling, using row cleaners, and processing additional (less) seed cotton. Revenues from cotton production were calculated by multiplying the price of cotton lint $(\$ 1.15 / \mathrm{kg}$; Agricultural Statistics Board, 2005) times the percentage lint turnout (0.41; Glass et al., 2004), times cotton yield plus the price of cotton seed (\$0.11/kg; Agricultural Statistics Board, 2005), times the remaining percentage of seed cotton yield after lint turnout. Additional production costs include the cost of rolling (\$7.72/ha), additional labor for using row cleaners $(\$ 0.59 / \mathrm{ha})$, and the additional cost (savings) from harvesting and ginning seed cotton $(\$ 0.22 / \mathrm{kg}$ ) (Mississippi State University, 2005). Given the potential time required to clear the row cleaners of debris, it was assumed that using row cleaners increased time for planting operations by $10 \%$. All prices and costs used were from 2004 to exclude variability in net returns due to market conditions.

Agronomic data were analyzed using the ANOVA (GLM procedure) in SAS (2001) with Dunnett's method for comparing treatment means. Economic data were analyzed using the GLM procedure in SAS (2001), and treatment means were compared using one-sided t-tests following Dunnett's procedure, to test which treatment combination statistically provided the highest net returns. All agronomic and economic tests were evaluated at a significance level of $\mathrm{P} \leq 0.10$.

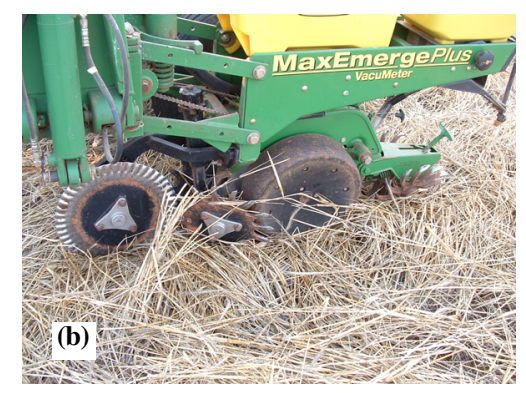




\section{Results AND Discussion}

The average height and dry biomass of rye in 2004 and 2005 growing seasons at the two locations are shown in table 1 . The average dry rye biomass at EVS was 6.23 tonnes/ ha in 2004 and 6.55 tonnes/ha in 2005. At TVS, the average biomass was 5.83 tonnes/ha in 2004 and dramatically reduced to 2.91 tonnes/ha in 2005 due to wet weather in the winter months (water ponding in the field in December 2004 and January 2005) and cool temperatures in March 2005, which negatively affected rye growth. No significant difference in dry biomass was found between rolling treatments; P-values ranged from 0.4540 and 0.9137 (table 1).

\section{Cotton Stand}

\section{Effect of Rolling Direction on Cotton Stand}

In 2004, significant differences in cotton stand were observed for all rolling treatments at EVS. The highest cotton stand was reported with parallel rolling, and the lowest stand occurred with perpendicular rolling (table 2). At TVS, the highest cotton stand was reported with no rolling and parallel rolling of the cover crop. There was no significant difference between these two treatments. At both locations, the lowest cotton stand was observed with perpendicular rolling.

In 2005, for EVS, no significant differences were found between rolling treatments. Similarly for TVS, there were no significant differences between rolling treatments (table 2). The lack of differences between rolling treatments in cotton stand was likely related to the reduced height and biomass of the rye. The biomass in 2005 was $56 \%$ less than in 2004 . Lower rye biomass may have resulted in reduced soil moisture, causing a decrease in cotton stand by $12 \%$ in comparison with 2004 .

\section{Effect of Row Cleaner Type on Cotton Stand}

In 2004, no significant differences in cotton stand were observed between Yetter, Dawn, and Dawn/no coulter at EVS. However, when compared with no row cleaner, cotton stand was significantly higher for all three row cleaners (table 3). At TVS, the highest cotton stand was reported for Yetter in comparison with Dawn, Dawn/no coulter, and no row cleaner (table 3 ).

In 2005, significantly higher stands were observed with the Yetter and Dawn row cleaners at EVS; Dawn/no coulter resulted in a $9 \%$ lower stand in comparison with the Dawn row cleaner. The lowest stand was with no row cleaner, which was 37\% lower than the Yetter and Dawn row cleaners. At TVS, the highest cotton stand was found with the Dawn row cleaner, which resulted in $15 \%$ higher cotton stand than

Table 1. Average rye height and biomass for the E.V. Smith (EVS) and Tennessee Valley (TVS) research stations.

\begin{tabular}{lccccc}
\hline & \multicolumn{2}{c}{2004} & & \multicolumn{2}{c}{2005} \\
\cline { 2 - 3 } \cline { 5 - 6 } \cline { 5 - 6 } & EVS & TVS & & EVS & TVS \\
\hline Height $(\mathrm{m})$ & 1.55 & 1.36 & & 1.28 & 0.91 \\
\hline Dry biomass (tonnes/ha) & by rolling treatment & & & \\
No rolling & 5.53 & 5.77 & & 5.52 & 2.82 \\
Parallel & 6.60 & 7.02 & & 5.82 & 3.34 \\
Diagonal & 6.39 & 6.64 & & 6.02 & 2.93 \\
Perpendicular & 6.39 & 6.67 & & 5.89 & 2.52 \\
\hline P-value & 0.4695 & 0.4540 & & 0.9137 & 0.9078 \\
Avg. dry biomass & 6.23 & 6.55 & & 5.83 & 2.91 \\
\hline
\end{tabular}

Table 2. Cotton stand (thousand plants per hectare) for 2004-2005 growing season for two locations with respect to rolling direction.[a]

\begin{tabular}{cccccc}
\hline \multirow{2}{*}{ Rolling } & \multicolumn{2}{c}{2004} & & \multicolumn{2}{c}{2005} \\
\cline { 2 - 3 } \cline { 5 - 6 } Treatment & EVS & TVS & & EVS & TVS \\
\hline No rolling & $129.0 \mathrm{c}$ & $139.0 \mathrm{c}$ & & 136.0 & 111.6 \\
Parallel & $140.8 \mathrm{~d}$ & $135.5 \mathrm{c}$ & & 135.8 & 121.1 \\
Diagonal & $117.5 \mathrm{~b}$ & $119.7 \mathrm{~b}$ & & 126.1 & 117.9 \\
Perpendicular & $101.7 \mathrm{a}$ & $103.2 \mathrm{a}$ & & 116.4 & 112.4 \\
\hline P-value & 0.0003 & 0.0822 & & 0.2280 & 0.8560
\end{tabular}

[a] Treatment means are compared for each year and location using Dunnett's procedure in SAS (2001). Treatment means followed by the same letter in each column are not statistically different. Treatment means with different letters are statistically different, in that the mean with the higher letter (e.g., c > a) has a mean statistically greater than the mean is it compared to.

Dawn/no coulter and no row cleaner and 20\% higher than Yetter.

\section{Combined Treatment Effects on Cotton Stand}

At $10 \%$ significant level, no significant interactions were found between rolling direction and row cleaner treatments at either location during 2004 and 2005 (table 4). However, in 2005 , a trend existed at TVS that in $85 \%$ of occurrences, the perpendicular rolling direction with or without row cleaner would not be recommended since the number of cotton plants per hectare was lower. Conversely, no-rolled rye residue or parallel rolling, both with a row cleaner present, appear to be better choices. At EVS in both years, in at least $70 \%$ of occurrences, the perpendicular rolling direction and no row cleaner is not a good combination, whereas parallel rolling or no-rolled rye is recommended, as long as a row cleaner is used. Visual observations during cotton planting showed that with rye residue in a perpendicular orientation to the planter, there were instances when the residue was not completely cut through by the coulter; thus, cotton seeds did not have adequate contact with the soil, and consequently "hair pinning" occurred, usually resulting in a lower plant stand.

\section{COTTON EMERGENCE RATE INDEX (ERI) \\ Effect of Rolling Direction on Cotton ERI}

Presented ERI values (table 5) are averaged across the other main effects (row cleaners). In 2004, the most rapid cotton emergence for EVS was obtained with parallel rolling, whereas the slowest emergence was with perpendicular rolling, which was significantly lower than no rolling. For TVS, the highest emergence rate was reported for no-rolled

Table 3. Cotton stand (thousand plants per hectare) for 2004-2005 growing season for two locations with respect to row cleaner type. [a]

\begin{tabular}{cccccc}
\hline \multirow{2}{*}{$\begin{array}{c}\text { Row Cleaner } \\
\text { Treatment }\end{array}$} & \multicolumn{2}{c}{2004} & & \multicolumn{2}{c}{2005} \\
\cline { 2 - 3 } \cline { 5 - 6 } & EVS & TVS & & EVS & TVS \\
\hline No row cleaner & $109.6 \mathrm{a}$ & $121.4 \mathrm{a}$ & & $91.6 \mathrm{a}$ & $113.8 \mathrm{a}$ \\
Dawn & $125.0 \mathrm{~b}$ & $121.2 \mathrm{a}$ & & $146.9 \mathrm{c}$ & $136.6 \mathrm{~b}$ \\
Dawn/no coulter & $123.8 \mathrm{~b}$ & $122.0 \mathrm{a}$ & & $132.0 \mathrm{~b}$ & $105.9 \mathrm{a}$ \\
Yetter & $130.6 \mathrm{~b}$ & $132.8 \mathrm{~b}$ & & $145.9 \mathrm{bc}$ & $106.6 \mathrm{a}$ \\
\hline P-value & 0.0681 & 0.0193 & & 0.0001 & 0.0028 \\
\hline
\end{tabular}

[a] Treatment means are compared for each year and location using Dunnett's procedure in SAS (2001). Treatment means followed by the same letter in each column are not statistically different. Treatment means with different letters are statistically different, in that the mean with the higher letter (e.g., c > a) has a mean statistically greater than the mean is it compared to. 
Table 4. Cotton stand (thousand plants per hectare) for 2004-2005 growing season for two locations with respect to rolling direction and row cleaner type.

\begin{tabular}{llccccc}
\hline Treatment Combinations & & \multicolumn{2}{c}{2004} & \multicolumn{2}{c}{2005} \\
\cline { 1 - 3 } \cline { 5 - 7 } Rolling & Row Cleaner & & EVS & TVS & EVS & TVS \\
\hline No rolling & No row cleaner & & 112.4 & 128.1 & 113.0 & 100.9 \\
& Dawn & & 125.4 & 149.1 & 144.5 & 140.5 \\
& Dawn/no coulter & & 144.8 & 137.2 & 149.3 & 100.9 \\
& Yetter & & 133.5 & 141.5 & 145.3 & 104.1 \\
\hline Parallel & No row cleaner & & 127.8 & 134.5 & 101.7 & 121.9 \\
& Dawn & & 142.4 & 136.7 & 147.7 & 138.8 \\
& Dawn/no coulter & & 142.4 & 131.9 & 146.1 & 113.0 \\
& Yetter & & 150.5 & 138.8 & 147.7 & 110.6 \\
\hline Perpen- & No row cleaner & & 93.8 & 102.8 & 71.8 & 118.7 \\
& Dawn & & 109.2 & 83.4 & 146.9 & 126.7 \\
& Dawn/no coulter & & 90.6 & 103.9 & 100.9 & 110.6 \\
& Yetter & & 113.2 & 122.7 & 146.1 & 93.6 \\
\hline Diagonal & No row cleaner & & 104.3 & 120.0 & 79.9 & 113.8 \\
& Dawn & & 123.0 & 115.7 & 148.5 & 140.5 \\
& Dawn/no coulter & 117.3 & 115.2 & 131.6 & 99.3 \\
& Yetter & 125.4 & 128.1 & 144.5 & 117.9 \\
\hline & P-value & 0.2692 & 0.1459 & 0.3033 & 0.7812 \\
\hline & & & & &
\end{tabular}

rye and parallel and diagonal rolling, and the lowest rate was with perpendicular rolling. In 2005 at EVS, the fastest emergence was found with no-rolled rye, whereas perpendicular rolling resulted in the slowest emergence. ERI values for parallel and diagonal rolling were significantly higher than for perpendicular rolling and lower than for no-rolled rye. In 2005 at TVS, no significant differences were found between all rolling treatments.

\section{Effect of Row Cleaner Type on Cotton ERI}

Higher ERI values indicate faster cotton emergence, and lower values indicate slower emergence. At EVS in 2004, the Yetter row cleaner resulted in the fastest emergence, and the slowest emergence was with no row cleaner. ERI values or Dawn and Dawn/no coulter were lower than for Yetter, but were higher than for no row cleaner (table 6). At TVS, a significantly higher ERI was found with the Yetter row cleaner compared with the other row cleaners, although there was no significant difference in ERI between no row cleaner, Dawn, and Dawn/no coulter. In 2005, the fastest emergence was measured for Dawn and Yetter at EVS, and the slowest was associated with no row cleaner. At TVS, the fastest emergence was measured for Dawn, and the slowest

Table 5. Cotton emergence rate index (ERI) for 2004-2005 growing season at two locations with respect to rolling direction. [a]

\begin{tabular}{cccccc}
\hline \multirow{2}{*}{ Rolling } & \multicolumn{2}{c}{2004} & & \multicolumn{2}{c}{2005} \\
\cline { 2 - 3 } \cline { 6 - 7 } Treatment & EVS & TVS & & EVS & TVS \\
\hline No rolling & $8.57 \mathrm{c}$ & $9.56 \mathrm{c}$ & & $10.68 \mathrm{c}$ & 7.87 \\
Parallel & $9.20 \mathrm{~d}$ & $9.32 \mathrm{c}$ & & $9.87 \mathrm{~b}$ & 8.31 \\
Diagonal & $7.13 \mathrm{~b}$ & $8.24 \mathrm{~b}$ & & $9.46 \mathrm{~b}$ & 7.88 \\
Perpendicular & $6.07 \mathrm{a}$ & $7.10 \mathrm{a}$ & & $8.60 \mathrm{a}$ & 7.93 \\
\hline P-value & 0.0001 & 0.0822 & & 0.0588 & 0.9355 \\
\hline
\end{tabular}

[a] Treatment means are compared for each year and location using Dunnett's procedure in SAS (2001). Treatment means followed by the same letter in each column are not statistically different. Treatment means with different letters are statistically different, in that the mean with the higher letter (e.g., c > a) has a mean statistically greater than the mean is it compared to.
Table 6. Cotton emergence rate index (ERI) for 2004-2005 growing seasons for two locations with respect to row cleaner type. ${ }^{[a]}$

\begin{tabular}{cccccc}
\hline Row Cleaner & \multicolumn{2}{c}{2004} & & \multicolumn{2}{c}{2005} \\
\cline { 2 - 3 } \cline { 5 - 6 } Treatment & EVS & TVS & & EVS & TVS \\
\hline No row cleaner & $6.49 \mathrm{a}$ & $8.35 \mathrm{a}$ & & $6.64 \mathrm{a}$ & $8.27 \mathrm{~b}$ \\
Dawn & $8.07 \mathrm{~b}$ & $8.34 \mathrm{a}$ & & $11.06 \mathrm{c}$ & $9.42 \mathrm{c}$ \\
Dawn/no coulter & $7.68 \mathrm{~b}$ & $8.40 \mathrm{a}$ & & $9.95 \mathrm{~b}$ & $7.81 \mathrm{~b}$ \\
Yetter & $8.73 \mathrm{c}$ & $9.14 \mathrm{~b}$ & & $10.94 \mathrm{c}$ & $6.50 \mathrm{a}$ \\
\hline P-value & 0.0011 & 0.0192 & & 0.0001 & 0.0005 \\
\hline
\end{tabular}

[a] Treatment means followed by the same letter in each column are not statistically different. Treatment means with different letters are statistically different, in that the mean with the higher letter (e.g., c > a) has a mean statistically greater than the mean is it compared to.

emergence was associated with Yetter. It is not clear why the slowest emergence occurred with the Yetter row cleaner. One possible cause is that the row cleaner did not move the residue from the planting path, and the coulter could not cut the residue and instead pushed the residue into the furrow, resulting in "hair pinning" and lower cotton emergence. As already reported for the Yetter row cleaner, cotton stand was significantly lower compared with the other row cleaners. The lower stand could be related to "hair pinning."

\section{Combined Treatment Effects on Cotton ERI}

In 2004 and 2005, there were significant interactions between rolling directions and row cleaner types at EVS but not at TVS (table 7). At EVS in 2004, the fastest emergence rate was reported for parallel rolling with Yetter, while the lowest rate was reported for perpendicular rolling with no row cleaner. As previously stated, there was unusually low rye height and biomass at TVS in 2005 . It appears that standing rye cover did not cause any interference for the planter equipped with the Dawn row cleaner and resulted in the fastest cotton emergence. The slowest emergence was reported for perpendicular rolling with no row cleaner in 2004 and diagonal rolling with Yetter in 2005.

\begin{tabular}{|c|c|c|c|c|c|}
\hline \multicolumn{2}{|c|}{ Treatment Combinations } & \multicolumn{2}{|c|}{2004} & \multicolumn{2}{|c|}{2005} \\
\hline Rolling & Row Cleaner & EVS & TVS & EVS & TVS \\
\hline \multirow[t]{4}{*}{ No rolling } & No row cleaner & $7.40 \mathrm{de}$ & 8.80 & $8.24 \mathrm{bc}$ & 7.23 \\
\hline & Dawn & 8.48 efgh & 10.25 & $11.84 \mathrm{~d}$ & 10.33 \\
\hline & Dawn/no coulter & $9.38 \mathrm{hi}$ & 9.45 & $11.48 \mathrm{~d}$ & 7.88 \\
\hline & Yetter & 9.01 fghi & 9.75 & $11.14 \mathrm{~d}$ & 6.08 \\
\hline \multirow[t]{4}{*}{ Parallel } & No row cleaner & 8.23 efg & 9.28 & $7.30 \mathrm{ab}$ & 8.83 \\
\hline & Dawn & $9.26 \mathrm{ghi}$ & 9.40 & $10.41 \mathrm{~d}$ & 9.35 \\
\hline & Dawn/no coulter & $9.39 \mathrm{hi}$ & 9.08 & $10.85 \mathrm{~d}$ & 8.10 \\
\hline & Yetter & $9.93 \mathrm{i}$ & 9.55 & $10.90 \mathrm{~d}$ & 6.98 \\
\hline \multirow{4}{*}{$\begin{array}{l}\text { Perpen- } \\
\text { dicular }\end{array}$} & No row cleaner & $4.56 \mathrm{a}$ & 7.10 & $5.43 \mathrm{a}$ & 8.28 \\
\hline & Dawn & $6.60 \mathrm{~cd}$ & 5.75 & $10.85 \mathrm{~d}$ & 9.25 \\
\hline & Dawn/no coulter & $5.42 \mathrm{ab}$ & 7.15 & $7.48 \mathrm{ab}$ & 8.13 \\
\hline & Yetter & $7.72 \mathrm{e}$ & 8.45 & $10.64 \mathrm{~d}$ & 6.10 \\
\hline \multirow[t]{5}{*}{ Diagonal } & No row cleaner & $5.79 \mathrm{bc}$ & 8.25 & $5.59 \mathrm{ab}$ & 8.73 \\
\hline & Dawn & $7.94 \mathrm{ef}$ & 8.00 & $11.15 \mathrm{~d}$ & 8.78 \\
\hline & Dawn/no coulter & $6.52 \mathrm{bcd}$ & 7.93 & $9.99 \mathrm{~cd}$ & 7.18 \\
\hline & Yetter & 8.27 efgh & 8.83 & $11.08 \mathrm{~d}$ & 6.83 \\
\hline & P-value & 0.0141 & 0.145 & 0.0852 & 0.4955 \\
\hline
\end{tabular}

Table 7. Combined treatment effect on statistically different. Treatment means with different letters are has a mean statistically greater than the mean is it compared to. 
Table 8. Average seed cotton yield (kg/ha) with respect to rolling direction.

\begin{tabular}{cccccc}
\hline \multirow{2}{*}{ Rolling } & \multicolumn{2}{c}{2004} & & \multicolumn{2}{c}{2005} \\
\cline { 2 - 3 } \cline { 5 - 6 } Treatment & EVS & TVS & & EVS & TVS \\
\hline No rolling & 1624 & 3738 & & 3622 & 3777 \\
Parallel & 1920 & 3757 & & 3747 & 3642 \\
Diagonal & 1453 & 3530 & & 3672 & 3582 \\
Perpendicular & 1618 & 3417 & & 3637 & 3581 \\
\hline P-value & 0.2516 & 0.2686 & & 0.9267 & 0.5181 \\
\hline
\end{tabular}

\section{CotTon YieLd}

\section{Effect of Rolling Direction on Cotton Yield}

There were no significant differences in cotton seed yield between rolling treatments (main effects) for each location in 2004 and 2005 (table 8). A considerable yield reduction was caused by Hurricane Ivan in 2004, which occurred during the harvesting period. Average cotton yield at EVS was $46 \%$ of the yield that was recorded at TVS.

\section{Effect of Row Cleaner Type on Cotton Yield}

As with rolling direction, no significant differences in cotton yield were found between row cleaners (sub-main effects) at both locations (table 9).

\section{Combined Treatment Effects on Cotton Yield}

In 2004, no interactions were found between rolling directions and row cleaners at EVS; however, interactions were significant at TVS. Significantly higher cotton yield was reported for no-rolled rye and the Yetter row cleaner compared to perpendicular and diagonal rolling with all row cleaner treatments (no row cleaner, Dawn, Dawn/no coulter, and Yetter). The lowest cotton yield was reported for perpendicular rolling with Dawn and might be associated with the inability of the coulter to completely cut the rye residue, thus causing "hair pinning." No significant differences in cotton seed yield were found between parallel rolling with all row cleaners and no-rolled rye with the row cleaners used in the experiment except for the Dawn row cleaner. Overall, no-rolled rye and parallel rolling with most row cleaner combinations were associated with higher cotton yields. In 2005, no interactions were found at TVS. The lack of significant differences in cotton seed yield was most likely associated with an unusually low biomass of rye (about 50\% less than reported for 2004 for TVS). However, interactions between rolling directions and row cleaners were significant at EVS. In particular, the combination of parallel rolling and no row cleaner produced the highest yield compared to perpendicular rolling and no row cleaner (table 10).

No significant differences between cotton seed yield were found for all row cleaner treatments used with parallel rolling. The data suggest that the higher cotton seed yield achieved with parallel rolling was a result of less interference between the rye residue and the planter, especially when no row cleaners were attached to the planter. Conversely, the lowest yield was obtained with perpendicular rolling without

Table 9. Average seed cotton yield $(\mathrm{kg} / \mathrm{ha})$ with respect to row cleaners.

\begin{tabular}{cccccc}
\hline \multirow{2}{*}{ Row Cleaner } & \multicolumn{2}{c}{2004} & & \multicolumn{2}{c}{2005} \\
\cline { 2 - 3 } \cline { 5 - 6 } Treatment & EVS & TVS & & EVS & TVS \\
\hline No row cleaner & 1563 & 3591 & & 3625 & 3886 \\
Dawn & 1674 & 3495 & & 3718 & 3501 \\
Dawn/no coulter & 1622 & 3622 & & 3644 & 3578 \\
Yetter & 1757 & 3735 & & 3690 & 3516 \\
\hline P-value & 0.4881 & 0.5045 & & 0.4547 & 0.8115 \\
\hline
\end{tabular}

Table 10. Combined treatment effect on seed cotton yield (kg/ha). ${ }^{[a]}$

\begin{tabular}{|c|c|c|c|c|c|}
\hline \multicolumn{2}{|c|}{ Treatment Combinations } & \multicolumn{2}{|c|}{2004} & \multicolumn{2}{|c|}{2005} \\
\hline Rolling & Row Cleaner & EVS & TVS & EVS & TVS \\
\hline \multirow{4}{*}{$\begin{array}{l}\text { No } \\
\text { rolling }\end{array}$} & No row cleaner & 1565 & 3675 bcde & $3613 \mathrm{abc}$ & 3957 \\
\hline & Dawn & 1572 & $3592 \mathrm{bc}$ & $3695 \mathrm{bc}$ & 3723 \\
\hline & Dawn/no coulter & 1654 & 3813 cde & $3619 \mathrm{abc}$ & 3855 \\
\hline & Yetter & 1709 & 3883 e & $3573 \mathrm{ab}$ & 3583 \\
\hline \multirow[t]{4}{*}{ Parallel } & No row cleaner & 1938 & 3701 bcde & $3869 \mathrm{c}$ & 3878 \\
\hline & Dawn & 1959 & 3809 cde & $3674 \mathrm{abc}$ & 3631 \\
\hline & Dawn/no coulter & 1871 & 3664 bcde & $3738 \mathrm{bc}$ & 3410 \\
\hline & Yetter & 1919 & 3866 de & $3717 \mathrm{bc}$ & 3259 \\
\hline \multirow{4}{*}{$\begin{array}{l}\text { Perpen- } \\
\text { dicular }\end{array}$} & No row cleaner & 1504 & $3535 \mathrm{~b}$ & 3442 a & 3758 \\
\hline & Dawn & 1617 & 3095 a & $3726 \mathrm{bc}$ & 3196 \\
\hline & Dawn/no coulter & 1501 & $3443 \mathrm{ab}$ & $3628 \mathrm{abc}$ & 3556 \\
\hline & Yetter & 1855 & $3607 \mathrm{bcd}$ & $3762 b c$ & 3826 \\
\hline \multirow[t]{5}{*}{ Diagonal } & No row cleaner & 1248 & $3463 \mathrm{~b}$ & $3589 \mathrm{ab}$ & 3962 \\
\hline & Dawn & 1553 & 3494 b & $3790 \mathrm{bc}$ & 3465 \\
\hline & Dawn/no coulter & 1468 & $3579 \mathrm{bc}$ & $3601 \mathrm{ab}$ & 3505 \\
\hline & Yetter & 1550 & 3596 bc & $3720 \mathrm{bc}$ & 3405 \\
\hline & P-value & 0.6922 & 0.0559 & 0.0649 & 0.1196 \\
\hline
\end{tabular}

[a] Treatment means followed by the same letter in each column are not statistically different. Treatment means with different letters are statistically different, in that the mean with the higher letter (e.g., c > a) has a mean statistically greater than the mean is it compared to.

row cleaners, suggesting that the absence of the coulter and row cleaner allowed only limited cutting through the residue by the planter's openers, without moving the residue from the planting path. Such a condition was most likely responsible for the poor seed contact with the soil, known as a "hair pinning." Perpendicular and diagonal rolling with no row cleaner and diagonal rolling with Dawn/no coulter also resulted in a lower cotton yields. These results suggest that for rolling directions other than parallel with respect to the planting direction, a coulter and row cleaner must be used to cut and move the rye residue from the planting path.

\section{Cotton STAND ANd Yield Correlation}

Getting a good cotton stand is important, and the potential cotton yield is determined during the first 30 to 40 days from planting (Deterling and El-Zik, 2006). To determine if there was a correlation between cotton stand and cotton yield, linear regression analyses were performed. In 2004, there was a poor correlation between plant stand and cotton yield for EVS (table 11). This poor correlation can be explained by the reduction of cotton yield that was caused by Hurricane Ivan. In contrast, at TVS, there was a strong positive correlation between stand and cotton yield with respect to rolling treatments $\left(\mathrm{R}^{2}=0.96\right)$ and a good correlation with respect to row cleaner treatments $\left(\mathrm{R}^{2}=0.75\right)$. In 2005 at TVS, a poor correlation between stand and yield was reported for rolling treatments, and no correlation was found with respect to row cleaner treatments. Similarly, at EVS, no correlation was observed for rolling treatments. However, at this location in 2005 , neither correlation affected cotton yield. Cotton can compensate for skips in stands and still produce an effective

\begin{tabular}{|c|c|c|c|c|}
\hline \multirow[b]{2}{*}{ Treatment } & \multicolumn{2}{|c|}{2004} & \multicolumn{2}{|c|}{2005} \\
\hline & EVS & TVS & EVS & TVS \\
\hline Rolling direction & 0.44 & 0.96 & 0.01 & 0.24 \\
\hline Row cleaner type & 0.84 & 0.75 & 0.70 & 0.04 \\
\hline
\end{tabular}


Table 12. Average time (s) required to clean the accumulated residue from row cleaners with respect to rolling direction and row cleaner treatments for TVS location in 2004 and EVS in 2005. [a]

\begin{tabular}{|c|c|c|c|c|c|c|c|c|c|}
\hline \multirow[b]{2}{*}{$\begin{array}{l}\text { Location } \\
\text { and Year }\end{array}$} & \multicolumn{5}{|c|}{ Rolling Treatment } & \multicolumn{4}{|c|}{ Row Cleaner Treatment } \\
\hline & $\begin{array}{c}\text { No } \\
\text { Rolling }\end{array}$ & Parallel & $\begin{array}{l}\text { Perpen- } \\
\text { dicular }\end{array}$ & Diagonal & $\begin{array}{c}\mathrm{P} \\
\text { Value }\end{array}$ & Dawn & $\begin{array}{c}\text { Dawn/ } \\
\text { No Coulter }\end{array}$ & Yetter & $\begin{array}{c}\mathrm{P} \\
\text { Value }\end{array}$ \\
\hline TVS 2004 & 57.42 & 7.75 & 0.58 & 2.58 & 0.1413 & 12.0 & 28.37 & 10.87 & 0.3229 \\
\hline EVS 2005 & $26.50 \mathrm{~b}$ & $12.33 \mathrm{a}$ & $7.08 \mathrm{a}$ & $12.50 \mathrm{a}$ & 0.0017 & 19.81 & 12.06 & 11.94 & 0.1327 \\
\hline
\end{tabular}

[a] Treatment means followed by the same letter in rows are not statistically different. Treatment means with different letters are statistically different, in that the mean with the higher letter (e.g., c > a) has a mean statistically greater than the mean is it compared to.

\begin{tabular}{|c|c|c|c|c|c|c|}
\hline \multirow{2}{*}{$\begin{array}{c}\text { Rolling } \\
\text { Treatment }\end{array}$} & \multicolumn{3}{|c|}{ TVS 2004} & \multicolumn{3}{|c|}{ EVS 2005} \\
\hline & Dawn & Dawn/No Coulter & Yetter & Dawn & Dawn/No Coulter & Yetter \\
\hline No rolling & 35.00 & 101.0 & 36.0 & 35.25 & 23.3 & 21.0 \\
\hline Parallel & 6.25 & 10.5 & 6.5 & 16.25 & 14.8 & 6.0 \\
\hline Perpendicular & 1.25 & 0.0 & 0.5 & 12.00 & 3.5 & 5.8 \\
\hline Diagonal & 5.5 & 1.75 & 0.5 & 15.75 & 6.8 & 15.0 \\
\hline P-value & \multicolumn{3}{|c|}{$0.4182(\mathrm{NS})$} & \multicolumn{3}{|c|}{$0.7587(\mathrm{NS})$} \\
\hline
\end{tabular}

Table 14. Mass (g) of accumulated residue from row cleaners with respect to rolling direction and row cleaner treatments for TVS location in 2004 and EVS in 2005.

\begin{tabular}{|c|c|c|c|c|c|c|c|c|c|c|c|}
\hline \multirow[b]{2}{*}{$\begin{array}{l}\text { Location } \\
\text { and year }\end{array}$} & \multicolumn{6}{|c|}{ Rolling Treatment } & \multicolumn{5}{|c|}{ Row Cleaner Treatment } \\
\hline & $\begin{array}{c}\text { No } \\
\text { Rolling }\end{array}$ & Parallel & $\begin{array}{l}\text { Perpen- } \\
\text { dicular }\end{array}$ & Diagonal & LSD & $\begin{array}{c}\mathrm{P} \\
\text { Value }\end{array}$ & Dawn & $\begin{array}{c}\text { Dawn/ } \\
\text { No Coulter }\end{array}$ & Yetter & LSD & $\begin{array}{c}\mathrm{P} \\
\text { Value }\end{array}$ \\
\hline TVS 2004 & 136.83 & 5.33 & 9.83 & 5.08 & NS & 0.1519 & 36.56 & 49.68 & 31.56 & NS & 0.1411 \\
\hline EVS 2005 & 7.67 & 0.67 & 0.00 & 0.50 & NS & 0.2139 & 0.31 & 0.00 & 6.31 & NS & 0.5184 \\
\hline
\end{tabular}

cotton yield. Jost and Steward (2005), who studied the effect of cotton skips on yield, reported that skips less than $0.6 \mathrm{~m} \mathrm{did}$ not reduce cotton yield.

\section{Time Required to Clean Accumulated RESIDUE ON Row CleANERS}

In 2004, cleaning time was recorded for the TVS location only. No cleaning was required at EVS because the cover crop was completely dry, partially decomposed, and did not accumulate on the row cleaners. In 2005, no cleaning time was recorded for TVS because the residue biomass was unusually low (2.2 times lower than in 2004) and did not create problems with residue accumulation on the row cleaners.

\section{TVS Location}

No significant differences in cleaning time were reported both for rolling treatments and row cleaner treatments (table 12). Although these differences were not significant at the $10 \%$ significance level, visual observations at cotton planting showed that, for perpendicular rolling, the coulter did not cut the residue completely and wedged some residue into the planting furrow. Another observation was that, when the coulter was removed from the Dawn row cleaner, uncut residue was easily pulled from the ground and was wrapped around spiked wheel cleaners.

\section{EVS Location}

Significant differences in cleaning time were observed between rolling treatments, with no-rolled rye contributing to the longest cleaning time compared to the other rolling treatments (table 12). No significant differences were observed between parallel, perpendicular, and diagonal rolling. Similarly, for row cleaner treatments, no significant differences were observed between Dawn, Dawn/no coulter, and Yetter. This lack of differences might be associated with the unusually low rye biomass at TVS in 2005. In 2004 and 2005 at both locations, no interactions were reported between combined treatment effects of rolling directions and row cleaner types (table 13).

\section{Mass of Residue Collected from Row Cleaners}

In 2004 at the EVS location, cleaning of rye residue from the row cleaners was not required. During cotton planting, rye residue did not accumulate on the row cleaners because the residue was dry and brittle, easily manageable by the row cleaners and even by the planter without row cleaners. Likewise, in 2005 at TVS, no accumulation of residue occurred on the row cleaners due to the unusually low biomass produced at that location. It appears that this lower amount of rye biomass was partially responsible for altering the amount of residue that accumulated on the row cleaners.

No significant differences in collected dry biomass on the row cleaners with respect to main effects (rolling directions and row cleaner types) were found at both locations (table 14). A trend existed in 2004 at TVS in which $85 \%$ more biomass was collected when the rye was not rolled and when the coulter was attached. There were no significant interactions between rolling and row cleaner treatment combinations at both locations. This might be associated with the high variability in the amount of collected residue within replications for each treatment (table 15).

\section{Net Returns from Cotton Production}

Table 16 lists the combined treatment effects of rolling direction and row cleaner type on changes in net revenues from the control (no roller, no row cleaner). In 2004 at EVS, net returns for all combinations of rolling direction and row cleaner were not significant $(\mathrm{P}$-value $=0.6922)$. Cotton seed yield was substantially reduced due to the hurricane in fall of 2004, which affected net returns. In 2004 at TVS, net return 
Table 15. Mass (g) of accumulated residue from row cleaners with respect to combined treatments for TVS in 2004 and EVS in 2005.

\begin{tabular}{|c|c|c|c|c|c|c|}
\hline \multirow{2}{*}{$\begin{array}{c}\text { Rolling } \\
\text { Treatment }\end{array}$} & \multicolumn{3}{|c|}{ TVS 2004} & \multicolumn{3}{|c|}{ EVS 2005} \\
\hline & Dawn & Dawn/No Coulter & Yetter & Dawn & Dawn/No Coulter & Yetter \\
\hline No rolling & 133.75 & 167.00 & 109.75 & 1.25 & 0.00 & 21.75 \\
\hline Parallel & 11.75 & 2.25 & 2.00 & 0.00 & 0.00 & 2.00 \\
\hline Perpendicular & 0.00 & 29.50 & 0.00 & 0.00 & 0.00 & 0.00 \\
\hline Diagonal & 0.75 & 0.00 & 14.50 & 0.00 & 0.00 & 1.50 \\
\hline P-value & \multicolumn{3}{|c|}{0.8697 (NS) } & \multicolumn{3}{|c|}{0.2766 (NS) } \\
\hline
\end{tabular}

Table 16. Combined treatment effects on changes in net returns (\$/ha) from no rolling, no row cleaner treatment. ${ }^{[a]}$

\begin{tabular}{|c|c|c|c|c|c|}
\hline \multicolumn{2}{|c|}{ Treatment Combinations } & \multicolumn{2}{|c|}{2004} & \multicolumn{2}{|c|}{2005} \\
\hline Rolling & Row Cleaner & EVS & TVS & EVS & TVS \\
\hline \multirow[t]{4}{*}{ No rolling } & No row cleaner & 0.00 & 0.00 cdefg & $0.00 \mathrm{abc}$ & 0.00 \\
\hline & Dawn & 1.08 & -24.14 bcdef & $22.66 \mathrm{bc}$ & -66.96 \\
\hline & Dawn/no coulter & 24.39 & $38.37 \mathrm{efg}$ & $1.08 \mathrm{abc}$ & -29.66 \\
\hline & Yetter & 39.93 & $58.23 \mathrm{~g}$ & -11.88 abc & -106.51 \\
\hline \multirow[t]{4}{*}{ Parallel } & No row cleaner & 97.19 & -0.90 bdefg & $64.38 \mathrm{c}$ & -30.42 \\
\hline & Dawn & 102.58 & $29.02 \mathrm{defg}$ & $8.47 \mathrm{a} b c$ & -101.01 \\
\hline & Dawn/no coulter & 77.55 & -12.08 bcdefg & $26.60 \mathrm{bc}$ & -163.70 \\
\hline & Yetter & 91.36 & $45.25 \mathrm{fg}$ & $20.56 \mathrm{bc}$ & -206.35 \\
\hline \multirow[t]{4}{*}{ Perpendicular } & No row cleaner & -25.42 & $-47.86 b c$ & $-56.50 \mathrm{a}$ & -64.61 \\
\hline & Dawn & 5.88 & $-173.02 \mathrm{a}$ & $23.15 \mathrm{bc}$ & -224.13 \\
\hline & Dawn/no coulter & -26.93 & $-74.42 \mathrm{~b}$ & $-4.48 a b$ & -122.42 \\
\hline & Yetter & 73.23 & -28.14 bcdef & $33.51 \mathrm{bc}$ & -45.93 \\
\hline \multirow[t]{4}{*}{ Diagonal } & No row cleaner & -97.94 & $-68.07 b c$ & $-15.06 \mathrm{ab}$ & -6.77 \\
\hline & Dawn & -12.26 & $-60.09 b c$ & $41.28 \mathrm{bc}$ & -148.15 \\
\hline & Dawn/no coulter & -36.43 & $-36.08 \mathrm{bcd}$ & $-12.25 \mathrm{ab}$ & -136.76 \\
\hline & Yetter & -13.12 & -31.07 bcde & $21.42 \mathrm{bc}$ & -164.90 \\
\hline \multicolumn{2}{|c|}{ P-value } & 0.6922 & 0.0559 & 0.0648 & 0.1197 \\
\hline
\end{tabular}

[a] Treatment means followed by the same letter in each column are not statistically different. Treatment means with different letters are statistically different, in that the mean with the higher letter (e.g., $c>a)$ has a mean statistically greater than the mean is it compared to.

from no rolling with the Yetter row cleaner was statistically greater than or equal to the other treatment combinations, providing an additional $\$ 58 /$ ha of return above the control. In 2005 , net returns for parallel rolling with no row cleaner and no-rolled rye with Dawn and Yetter row cleaners were statistically greater than the other treatment combinations at this location. In 2005 at TVS, there were no significant differences in change of net returns among all treatment combinations. Although the net returns were not significant (at the 0.1 significance level), negative numbers in net returns are most likely associated with the great reduction of rye biomass in 2005 at TVS. Differences across locations may be due to the accumulation and decomposition rate of cover and cash crop biomass, as well as climate. In terms of rolling direction, parallel rolling and no rolling provided the highest returns on average at EVS and TVS, respectively. Perpendicular and diagonal rolling provided the lowest returns. These results follow from the analyses that examined cotton stand, emergence, and yield. Given the low cost of installing row cleaners on an existing planter, these results provide evidence that use of row cleaners in high-residue conservation tillage systems is economically beneficial, although not always statistically significant, when the cover crop is not rolled or is rolled parallel to the planting operation.

\section{Summary AND CONCLUSIONS}

In 2004, parallel rolling (i.e., rolling rye and planting cotton performed in the same direction) generated the highest cotton stand at EVS, whereas at TVS the parallel rolling treatment and the no-rolled rye treatment generated the highest stand. The worst rolling directions with respect to cotton stand were perpendicular and diagonal. In 2005, there were no significant differences in cotton stand between rolling treatments at both locations. Significant differences were observed between row cleaner treatments in both years and at both locations. In 2004 at EVS, use of no row cleaner resulted in the lowest cotton stand, whereas higher cotton stand was observed with the Dawn and Yetter row cleaners. In 2004 at TVS, higher cotton stand was reported for Yetter, and lower stand was associated with no row cleaner, Dawn, and Dawn/no coulter. In 2005 at EVS, lower cotton stand was observed with no row cleaner, and higher stand was found with Dawn (with coulter) and Yetter. At TVS, Dawn with coulter generated higher cotton stand, in contrast to no row cleaner, while Dawn/no coulter and Yetter generated lower cotton stands. Based on these findings, parallel rolling and either type of row cleaner are recommended to obtain a higher cotton stand in no-till systems.

Planting cotton into no-rolled rye will not affect the cotton stand as long as row cleaners are used. However, this practice is limited to very low height and biomass of rye, i.e., less than $1 \mathrm{~m}$ tall and less than 3 tonnes/ha. When the rye height exceeds $1.2 \mathrm{~m}$, rolling would be required before planting cotton. Perpendicular and diagonal rolling directions are not recommended.

Based on the emergence rate index (ERI), the fastest emergence was observed with parallel rolling and with no-rolled rye at the two locations during 2004 and 2005. The slowest emergence was observed with perpendicular and 
diagonal rolling. The Yetter row cleaner had the fastest emergence at both locations in 2004 and at EVS in 2005. Dawn also had relatively fast emergence in 2005 at both locations. The fastest emergence was obtained with parallel rolling and both row cleaners. In 2005, no-rolled rye and both row cleaners provided the fastest cotton emergence at TVS.

The highest cotton yield was associated with parallel rolling and no-rolled rye. Dawn, Yetter, and no row cleaner also influenced the highest cotton yield. The best combination with respect to the highest cotton yield was parallel rolling and both row cleaners. In 2004, the highest net returns from cotton production were achieved with parallel rolling and the Dawn row cleaner at EVS, and with no rolling and the Yetter row cleaner at TVS. In 2005, the highest net returns were with parallel rolling and no row cleaner at EVS, and with no rolling and no row cleaner at TVS.

In 2004, a poor correlation between seed emergence and cotton yield was reported at EVS, whereas a strong correlation between seed emergence and cotton yield occurred at TVS. Neither correlation affected cotton yield. The longest cleaning time for residue accumulated on the row cleaners was associated with no-rolled rye and all row cleaner treatments. The highest mass of residue collected from the row cleaners was also related to no-rolled rye and both row cleaners.

Based on the results of this study, the following recommendations for rolling direction and row cleaner are:

- When rye is tall and produces a large amount of residue, parallel rolling and the Dawn or Yetter row cleaner are recommended.

- When rye is short and produces a low amount of biomass, no row cleaners are required with the parallel rolling direction, or cotton could be planted into standing rye with the Dawn or Yetter row cleaners.

- Regardless of the height and amount of residue produced by rye, perpendicular and diagonal rolling directions are not recommended.

- Parallel rolling minimized accumulation of residue on the row cleaners and minimized the cleaning time for the accumulated residue.

\section{ACKNOWLEDGEMENTS}

The authors wish to thank Mr. Quentin Stoll and Mr. Morris Welch for their invaluable assistance in conducting field experiment and data collection.

\section{REFERENCES}

Agricultural Statistics Board. 2005. Agricultural Prices: 2004 Summary. Document No. Pr 1-3 (05)a. Washington D.C.: USDA National Agricultural Statistics Service. Available at: http://usda.mannlib.cornell.edu/usda/nass/AgriPricSu//2000s/20 05/AgriPricSu-08-16-2005.pdf. Accessed 18 January 2006.

Ashford, D. L., and D. W. Reeves. 2003. Use of a mechanical roller crimper as an alternative kill method for cover crop. American J. Alternative Agric. 18(1): 37-45.

CTIC. 2004. Conservation tillage trends 1990-2004. National Crop Residue Management Survey. West Lafayette, Ind.: Conservation Technology Information Center.
Derpsch, R., C. H. Roth, N. Sidiras, and U. Köpke. 1991. Controle da erosão no Paraná, Brasil: Sistemas de cobertura do solo, plantio directo e prepare conservacionista do solo. Eschborn, Germany: Deutsche Gesellschaft für Technische Zusammenarbeit (GTZ)

Deterling, D., and K. M. El-Zik. 2006. How a cotton plant grows. Lubbock, Tex.: Texas A\&M University, Texas A\&M AgriLife Extension. Available at: http://lubbock.tamu.edu/cottoncd/ east/docs/genprod/cotplantgrows.pdf.

Dinnes, D. L., D. L. Karlen, D. B. Jaynes, T. C. Kasper, J. L. Hatfield, T. S. Colvin, and, C. A. Cambardella. 2002. Nitrogen management to reduce leaching in the tile-drained Midwestern soils. Agron. J. 94(1): 153-171.

Erbach, D. C. 1982. Tillage for continuous corn and corn-soybean rotation. Trans. ASAE 25(4): 906-911, 918.

Glass, K. M., C. D. Monks, C. H. Burmester, and E. van Santen. 2004. 2003 Alabama cotton variety report. Agronomy and Soils Departmental Series No. 257. Auburn, Ala.: Auburn University, Alabama Agricultural Experiment Station.

Hargrove, W. L., and W. W. Frye. 1987. The need for legume cover crops in conservation tillage production. In The Role of Legumes in Conservation Tillage Systems, 1-5. J. F. Power, ed. Ankeny, Iowa: Soil Conservation Society of America.

Jost, P., and A. Steward. 2005. Effect of skippy cotton on yield. Paper of the ASA Southern Regional Branch Conf. (June 19-21, 2005). Madison, Wisc.: American Society of Agronomy.

Kasper, T. C., J. K. Radke, and J. M. Laflen. 2001. Small grain cover crops and wheel traffic effects on infiltration, runoff, and erosion. J. Soil Water Conserv. 56(2): 160-164.

Kern, J. S., and M. G. Johnson. 1993. Conservation tillage impacts on national soils and atmospheric carbon levels. SSSA J. 57(1): 200-210.

Kornecki, T. S., A. J. Price, and R. L. Raper. 2006. Performance of different roller designs in terminating rye cover crop and reducing vibration. Applied Eng. in Agric. 22(5): 633-641.

McGregor, K. C., and C. K. Mutchler. 1992. Soil loss from conservation tillage for sorghum. Trans. ASAE 35(6): 1841-1845.

Mississippi State University. 2005. Cotton 2005 planning budgets. Budget Report 2005-01. Mississippi State, Miss.: Mississippi State University, Department of Agricultural Economics.

Nelson, J. E., K. D. Kephart, A. Bauer, and J. F. Connor. 1995. Growth stage of wheat, barley, and wild oat. Columbia, Mo.: University of Missouri. Available at: http://plantsci. missouri.edu/cropsys/growth.html.

Raper, R. L., D. W. Reeves, C. H. Burmester, and E. B. Schwab. 2000a. Tillage depth, tillage timing, and cover crop effects on cotton yield, soil strength, and tillage energy requirements. Applied Eng. in Agric. 16(4): 379-385.

Raper, R. L., D. W. Reeves, E. B. Schwab, and C. H. Burmester. 2000b. Reducing soil compaction of Tennessee Valley soils in conservation tillage systems. J. Cotton Sci. 4(2): 84-90.

Raper, R. L., P. A. Simonescu, T. S. Kornecki, A. J. Price, and D. W. Reeves. 2004. Reducing vibration while maintaining efficacy of rollers to terminate cover crops. Applied Eng. in Agric. 20(5): 581-584.

Reeves, D. W. 1994. Cover crops and rotations. In Advances in Soil Science: Crops Residue Management, 125-172. J. L. Hatfield and B. A. Stewart, eds. Boca Raton, Fla.: Lewis Publishers.

SAS. 2001. Proprietary Software Release 8.2. Cary, N.C. SAS Institute, Inc.

Snapp, S. S., S. M. Swinton, R. Labarta, D. Mutch, J. R. Black, R. Leep, J. Nyiraneza, and K. O'Neil. 2005. Evaluating cover crops for benefits, costs, and performance within cropping niches. Agron. J. 97(1): 322-332. 
